\title{
Essential iris atrophy
}

INSERM

\section{Source}

INSERM. (1999). Orphanet: an online rare disease and orphan drug data base. Essential iris atrophy. ORPHA:98981

Essential iris atrophy is a clinical variant of iridocorneal endothelial (ICE) syndrome (see this term), characterized by progressive iris atrophy and holes present on the surface of the iris, corneal edema, corectopia, uveal ectropion and anterior synechiae. Secondary glaucoma is also a common complication of the disease. 